\title{
Body size-based trophic structure of a deep marine ecosystem
}

\author{
Sonia Romero-Romero, ${ }^{1}$ Axayacatl Molina-Ramírez, Juan Höfer, And José Luis Acuña \\ Área de Ecología, Departamento de Biología de Organismos y Sistemas, Universidad de Oviedo, \\ Catedrático Rodrigo Uría s/n, 33071 Oviedo, Asturias, Spain
}

\begin{abstract}
Nitrogen stable isotope ratios $\left(\delta^{15} \mathrm{~N}\right)$ and body size were used to describe the size-based trophic structure of a deep-sea ecosystem, the Avilés submarine Canyon (Cantabrian Sea, Southern Bay of Biscay). We analyzed $\delta^{15} \mathrm{~N}$ of specimens collected on a seasonal basis (March 2012, October 2012, and May 2013), from a variety of zones (benthic, pelagic), taxa (from zooplankton through invertebrates and fishes to giant squids and cetaceans), or depths (from surface to $4700 \mathrm{~m}$ ) that spanned nine orders of magnitude in body mass. Our data reveal a strong linear dependence of trophic level on body size when data were considered either individually, aggregated into taxonomical categories, or binned into size classes. The three approaches render similar results that were not significantly different and yielded predator:prey body mass ratios (PPMR) of 1156:1, 3792:1 and 2718:1, respectively. Thus, our data represent unequivocal evidence of interspecific, size-based trophic structure of a whole ecosystem based on taxonomic/functional categories. We studied the variability in $\delta^{15} \mathrm{~N}$ not explained by body mass $(W)$ using linear mixed modeling and found that the $\delta^{15} \mathrm{~N}$ vs. $\log _{10} W$ relationship holds for both pelagic and benthic systems, with benthic organisms isotopically enriched relative to pelagic organisms of the same size. However there is a marked seasonal variation potentially related to the recycling state of the system.
\end{abstract}

Key words: body size; deep-sea; food web; predator-prey; size-based; stable isotopes; trophic structure.

\section{INTRODUCTION}

Body size is a key attribute in studies of aquatic food webs. It provides a surrogate measure for rates of respiration and production, mortality, predation, and for other important life-history traits (Peters 1983, Woodward et al. 2005). It is also used to describe food web structure and energy flux, since body size is also related to trophic level (Sheldon et al. 1972, Dickie et al. 1987). Historically, demonstration of this particularly important generalization relied on the simultaneous assessment of body size and diet, usually through theoretical analyses (Dickie et al. 1987), painstaking gut content analyses (Hyslop 1980, Jacob et al. 2011), literature review of feeding habits (Warren 1989) or laborious observations in the field and laboratory (Warren 1989, Jacob et al. 2011). However, since the discovery of stable isotopes as both natural tracers and as means of characterizing trophic structure, their use in ecology has increased rapidly and has enabled empirical approaches (Jennings et al. 2008). Nitrogen stable isotope analysis provides a direct and continuous measure of trophic position since the $\delta^{15} \mathrm{~N}$ of a consumer is enriched on average by $3.4 \%$ relative to its diet (Minagawa and Wada 1984). Most previous studies that examined

Received: 5 February 2015; Revised: 24 June 2015; Accepted: 14 July 2015. Corresponding Editor: S. A. Navarrete.

${ }^{1}$ E-mail: romeroromerosonia@gmail.com the relationship between trophic level and body size using stable isotopes have focused on a specific compartment [e.g., benthic (France et al. 1998, Jennings et al. 2002a); pelagic (Bode et al. 2007); demersal fish communities (Jennings et al. 2001, Al-Habsi et al. 2008); zooplankton (Fry and Quiñones 1994)]. Studies including samples of both pelagic and benthic organisms are scarce (Akin and Winemiller 2008, Persaud et al. 2011) and none of them include planktonic and nektonic as well as benthic organisms. Accordingly, there are claims for comprehensive isotope enrichment studies covering the full body size, taxonomic, and habitat spectrum (Jennings et al. 2008).

The trophic level can be mainly predicted from body size (Cohen et al. 2003), thereby, food web structures can be characterized using size-based approaches, which have been proposed as meaningful indicators for ecosystem-based management (Rochet and Trenkel 2003, Jennings and Dulvy 2005); allowing trophic studies in species-rich ecosystems with complex trophic pathways. In addition, temporal and spatial changes in body size spectra would reflect changes in trophic structure that could be used to assess and predict ecological responses to perturbations in threatened ecosystems (e.g., Pinnegar et al. 2002).

Information on the biodiversity, structure, and function of deep-sea ecosystems is still insufficient to 
adequately estimate their vulnerability to anthropogenic impacts (Mengerink et al. 2014). Canyon benthic communities are among the most vulnerable of those systems (Ramirez-Llodra et al. 2011). This is important, since they influence water mass dynamics, channel large volumes of sediments and organic matter from the shelf to the deep ocean (Canals et al. 2006) and support very productive and diverse communities (De Leo et al. 2010).

The main objective of this study is to characterize the trophic position of the most relevant functional groups present in the Avilés submarine Canyon (AC) as determined from nitrogen stable isotope signatures. We also examined the size-dependence of trophic structure and its variability. To our knowledge this is the first size-based trophic study of a deep sea food web and it is the first that integrates benthic and pelagic organisms within a size spectrum spanning nine orders of magnitude.

\section{Methods}

The AC is part of a complex network of canyons and valleys off the Central Cantabrian Coast with a depth range from $128 \mathrm{~m}$ at its head, located at only $12 \mathrm{~km}$ off the Avilés coast, down to $4766 \mathrm{~m}$ depth when it reaches the abyssal plain of the Bay of Biscay (Gómez-Ballesteros et al. 2014; Fig. 1). It is composed of a tributary channel and several other secondary channels that flow into the former, and the system is supplied with continental sources from the Nalón River. We extended our sampling area from $44^{\circ} 23^{\prime}$ to $43^{\circ} 56^{\prime} \mathrm{N}$ and from $6^{\circ} 31^{\prime}$ to $5^{\circ} 47^{\prime} \mathrm{W}$ (Fig. 1).

\section{Sampling methods}

Samples were collected during three oceanographic cruises that took place between 3 and 13 March 2012 (BIOCANT 1); between 27 September and 6 October 2012 (BIOCANT 2) and between 24 April and 4 May 2013 (BIOCANT 3) onboard the research vessel B/O Sarmiento de Gamboa at six different stations distributed on the main axis of the AC (stations C3, C5, C6, and C8) and on the adjacent slope (stations P3 and TP; Fig. 1). At each station, a rosette sampler was used to obtain profiles of temperature, salinity, and fluorescence by means of a CTD (conductivitytemperature-depth) probe Sea-Bird 911-plus (Sea-Bird Electronics, Bellevue, Washington, USA) mounted on the rosette, and water samples for the measurement of chlorophyll $a$ (chl $a$ ). At each station, we also sampled nekton by double oblique hauls with a $10 \mathrm{~mm}$ pore size Isaacs-Kidd Midwater Trawl net (IKMT), and mesozooplankton by oblique tows of a Multiple Opening/Closing Net and Environmental Sensing System (MOCNESS) equipped with eight nets of $200 \mu \mathrm{m}$ mesh size. Mesozooplankton samples were taken from 0 to $1200 \mathrm{~m}$ in stations C3, P3, and TP and from 0 to $2000 \mathrm{~m}$ in $\mathrm{C} 5, \mathrm{C} 6$, and $\mathrm{C} 8$ (Fig. 1). The benthic community was sampled with a $5 \mathrm{~m}$ wide Agassiz dredge hauled at the bottom floor during $1 \mathrm{~h}$ or by means of a rock dredge also hauled during $1 \mathrm{~h}$ when the bottom substrate was rocky. In addition, muscle tissue samples of cetaceans Delphinus delphis, Stenella coeruleoalba, and Physeter microcephalus, sea birds Morus bassanu and giant squid Architeuthis dux were obtained from individuals stranded on the coast (Fig. 1) and stored frozen at $-20^{\circ} \mathrm{C}$ for further analysis of stable isotopes.

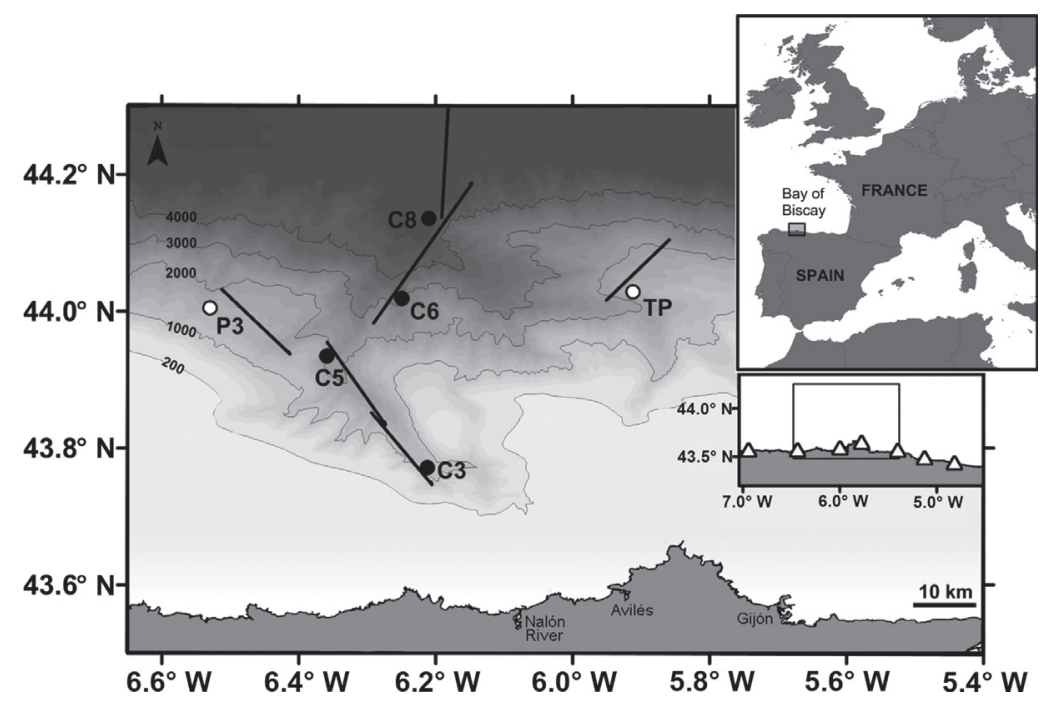

FIG. 1. Map of the study area, the Avilés Canyon System (AC), Spain. Dots indicate locations of stations and lines refer to the trawling of nets and dredges. Solid dots indicate the stations situated along the main axis of the AC and open dots indicate those on the adjacent slope. Triangles point out sites where giant squid and cetaceans were found stranded. 


\section{Sample processing}

Samples for chl $a$ were obtained by filtration of $200 \mathrm{~mL}$ of water on Millipore membrane filters and stored frozen at $-20^{\circ} \mathrm{C}$ in dark. Chl $a$ was extracted in $10 \mathrm{~mL}$ of $90 \%$ acetone during $24 \mathrm{~h}$ in darkness at $4^{\circ} \mathrm{C}$. Then chl $a$ concentrations were measured using a Turner Designs 10 fluorometer (Turner Designs, Sunnyvale, California, USA). Chl $a$ measurements were used to calibrate the fluorescence profiles. Each zooplankton sample was divided into two halves using a Motoda box-splitter. One half was fixed in a $4 \%$ formaldehyde sea-water-buffered solution and the other half was transferred to Whatman glass-fiber GF/A filters and immediately stored frozen at $-20^{\circ} \mathrm{C}$. For stable isotope analysis, each frozen zooplankton sample was thawed and the individuals were sorted according to their taxonomic group (Table 1). To obtain $1 \mathrm{mg}$ sample of dry weight for the isotope analysis, several individuals belonging to the same taxonomic group were pooled together. Zooplankton and nekton collected using the IKMT and macrobenthos collected with the dredges were sorted individually according to coarse taxonomic categories and three individuals of each group per station were selected for stable isotope analysis, if available. Each specimen was weighed and photographed onboard on a Kaiser rePRO 5602 motorized reprography column (Kaiser Fototechnik GmbH \& Company KG, Buchen, Germany) with a Canon EOS Mark III DSLR camera (Canon, Tokyo, Japan) and a small sample of muscle tissue, was dissected and stored frozen in Eppendorf tubes at $-20^{\circ} \mathrm{C}$ for later isotopic analysis (the body wall was used in the case of cnidarians, holothurians, and sea urchins).

TABLE 1. Taxonomic groups used in the study.

\begin{tabular}{|c|c|c|c|c|c|}
\hline Taxonomic group & Codes & $N$ & $\delta^{15} \mathrm{~N}(\%)$ & Body mass (g) & $\mathrm{TL}$ \\
\hline Cymbulia peronii & $\mathrm{Cp}$ & 8 & $5.6 \pm 0.7$ & & $2.0 \pm 0.2$ \\
\hline Copepoda & cop & 258 & $6.5 \pm 2.3$ & $3.85 \times 10^{-3} \pm 9.24 \times 10^{-3}$ & $2.3 \pm 0.7$ \\
\hline Ostracoda & ost & 32 & $6.7 \pm 1.6$ & $1.02 \times 10^{-3} \pm 4.86 \times 10^{-4}$ & $2.3 \pm 0.5$ \\
\hline Amphipoda & amp & 11 & $6.9 \pm 1.4$ & $1.76 \times 10^{-1} \pm 4.30 \times 10^{-1}$ & $2.4 \pm 0.5$ \\
\hline Euphausiacea & eup & 40 & $7.4 \pm 1.5$ & $1.45 \times 10^{-1} \pm 1.72 \times 10^{-1}$ & $2.5 \pm 0.5$ \\
\hline Pelagic Decapoda & pde & 102 & $8.6 \pm 1.8$ & $2.67 \pm 5.25$ & $2.8 \pm 0.6$ \\
\hline Pelagic Pisces & ppi & 64 & $9.1 \pm 1.5$ & $6.07 \pm 1.35 \times 10^{1}$ & $3.0 \pm 0.5$ \\
\hline Chaetognatha & cha & 33 & $9.9 \pm 2.3$ & $2.55 \times 10^{-2} \pm 3.45 \times 10^{-2}$ & $3.3 \pm 0.7$ \\
\hline Anthozoa & ant & 27 & $10.1 \pm 2.2$ & & $3.3 \pm 0.6$ \\
\hline Cirripedia & $\operatorname{cir}$ & 5 & $10.2 \pm 1.1$ & $1.14 \pm 1.19$ & $3.4 \pm 0.2$ \\
\hline Benthic Decapoda & bde & 29 & $10.5 \pm 1.4$ & $4.78 \pm 9.63$ & $3.4 \pm 0.4$ \\
\hline Gasteropoda & gas & 6 & $10.5 \pm 1.1$ & $3.42 \pm 2.21$ & $3.5 \pm 0.9$ \\
\hline Ophiuroidea & oph & 35 & $10.9 \pm 1.8$ & $1.02 \pm 1.80$ & $3.6 \pm 0.5$ \\
\hline Polychaeta & pol & 44 & $11.3 \pm 1.4$ & $2.50 \pm 5.39$ & $3.7 \pm 0.5$ \\
\hline Pycnogonida & pyc & 4 & $11.6 \pm 0.9$ & $5.01 \pm 7.95$ & $3.8 \pm 0.3$ \\
\hline Cephalopoda & cep & 6 & $11.7 \pm 1.2$ & $1.51 \times 10^{2} \pm 3.49 \times 10^{2}$ & $3.8 \pm 0.3$ \\
\hline Echinoidea & ech & 8 & $11.9 \pm 1.7$ & $6.74 \times 10^{1} \pm 8.10 \times 10^{1}$ & $3.8 \pm 0.5$ \\
\hline Delphinidae & del & 7 & $12.1 \pm 0.7$ & $9.26 \times 10^{4} \pm 1.27 \times 10^{4}$ & $3.9 \pm 0.2$ \\
\hline Benthic Pisces & bpi & 78 & $12.1 \pm 1.5$ & $2.49 \times 10^{2} \pm 4.76 \times 10^{2}$ & $3.9 \pm 0.4$ \\
\hline Holothuroidea & hol & 27 & $12.4 \pm 1.9$ & $6.48 \times 10^{1} \pm 1.07 \times 10^{2}$ & $4.0 \pm 0.6$ \\
\hline Sipuncula & $\operatorname{sip}$ & 5 & $12.6 \pm 1.4$ & $3.40 \times 10^{1} \pm 5.85 \times 10^{1}$ & $4.1 \pm 0.4$ \\
\hline Brachiopoda & bra & 8 & $12.7 \pm 1.5$ & $3.31 \pm 3.44$ & $4.1 \pm 0.4$ \\
\hline Isopoda & iso & 5 & $12.9 \pm 2.1$ & $5.58 \times 10^{-1} \pm 1.71 \times 10^{-1}$ & $4.2 \pm 0.6$ \\
\hline Porifera & por & 9 & $13.2 \pm 2.7$ & & $4.2 \pm 0.8$ \\
\hline Aves & ave & 9 & $13.4 \pm 1.3$ & $1.80 \times 10^{3} \pm 2.08 \times 10^{2}$ & $4.3 \pm 0.4$ \\
\hline Asteroidea & ast & 32 & $14.4 \pm 2.3$ & $1.02 \times 10^{1} \pm 1.27 \times 10^{1}$ & $4.6 \pm 0.7$ \\
\hline Architeuthis dux & Ad & 3 & $14.7 \pm 0.1$ & $8.93 \times 10^{4} \pm 4.48 \times 10^{4}$ & $4.7 \pm 0.0$ \\
\hline Physeter macrocephalus & $\mathrm{Pm}$ & 1 & 16.8 & $2.50 \times 10^{6}$ & 5.3 \\
\hline
\end{tabular}

Notes: Stable nitrogen isotope values, body mass calculated, and corresponding derived trophic level (TL; mean \pm SD) are presented. Empty cells mean that we have no measure of body size for those taxonomic groups. 
Due to their high diversity, the taxonomic identification of the specimens collected is still underway, and only a small percentage of the individuals have been determined to species level. Of these, most were identified according to morphological characteristics, and a few by means of their cytochrome c oxidase subunit 1 (COI) barcoding sequence (Hebert et al. 2003). In an attempt to consider this diversity, we have classified the specimens according to meaningful taxonomic/functional categories.

\section{Body size}

Body mass was used as indicator of body size. Organisms were weighed on board using Pesola Micro-Line spring scales (Pesola AG, Baar, Switzerland), models 20010, 20030, 20060, 20100, 20300, and 40600, which measured up to $10,30,60,100,300$, and $600 \mathrm{~g}$ with precisions of $0.10,0.25,0.50,1,2$, and $5 \mathrm{~g}$, respectively. For specimens heavier than $600 \mathrm{~g}$, we used a hanging scale. These measures are less precise for small organisms or for specimens that are usually not complete (e.g., ophiuroids), so when there was a conversion factor available in the literature for each species or for taxonomically close organisms, body mass was calculated from body length (see Supplement). Body length was measured from the pictures taken on board of each organism using image analysis software ImageJ (Abràmoff et al. 2004). According to its body mass, each specimen was assigned to a logarithmic $\left(\log _{10}\right)$ body size class (i.e., the first class was $10^{-5}$ to $10^{-4} \mathrm{~g}$, the next was $10^{-4}$ to $10^{-3} \mathrm{~g}$, and so on up to $10^{7} \mathrm{~g}$ ). We then used all individuals within a given size class to calculate its average body size and $\delta^{15} \mathrm{~N}$. Cymbulia peronii and those colonial organisms (i.e., taxonomic groups Anthozoa and Porifera) that could not be weighed individually were not included in the $\delta^{15} \mathrm{~N}$ vs. $\log _{10}$ (body mass) relationship analysis.

\section{Stable isotope analyses}

All samples for isotopic determination were dried at $60^{\circ} \mathrm{C}$ for $48 \mathrm{~h}$, ground to a fine powder with pestle and mortar, packed in $3.3 \times 5 \mathrm{~mm}$ tin capsules and processed in a Thermo Finnigan Mat Delta Plus isotope-ratio mass spectrometer (Thermo Fisher Scientific, Waltham, Massachusetts, USA) coupled to a Carlo Erba CHNSO 1108 elemental analyzer (Thermo Fisher Scientific). Stable isotope abundances were expressed in $\delta$ notation as the deviation from standards in parts per thousand (\%o) according to the following equation:

$$
\delta^{15} \mathrm{~N}=\left[\left(R_{\text {sample }} / R_{\text {standard }}\right)-1\right] \times 1000
$$

where $R$ is the ratio ${ }^{15} \mathrm{~N} /{ }^{14} \mathrm{~N}$. The $R_{\text {standard }}$ values were based on atmospheric $\mathrm{N}_{2}$ (AIR). Replicate measurements of internal laboratory standards indicate measurement errors of $\pm 0.15 \%$ o for $\delta^{15} \mathrm{~N}$. The trophic level (TL) of consumers in the AC food web was estimated using the equation given by Vander Zanden and Rasmussen (2001)

$$
\mathrm{TL}=\left(\delta^{15} \mathrm{~N}_{\text {consumer }}-\delta^{15} \mathrm{~N}_{\text {baseline }}\right) / 3.4+\lambda
$$

assuming a constant trophic fractionation of $3.4 \%$ (Minagawa and Wada 1984) and where $\lambda$ is the trophic position of the organism used as the $\delta^{15} \mathrm{~N}_{\text {baseline }}$ of the food web. Ideally, isotopic ratios for phytoplankton should be used as baseline levels representing the first trophic level in the food web (i.e., TL = 1). However, it is difficult to routinely isolate phytoplankton from seston or plankton samples for isotope composition analyses, thus herbivores are frequently favored as baseline organisms representative of the second trophic level (TL $=2$; Post 2002). Consequently, we used the thecosomate gasteropod Cymbulia peronii (mean $\delta^{15} \mathrm{~N}=5.6 \pm 0.7, n=8$ ) as representative of a $\mathrm{TL}=2$, assuming that it is predominantly primary consumer (as in Valls et al. 2014).

\section{Statistical methods}

We used linear regression models to explore the relationship between the dependent variable $\delta^{15} \mathrm{~N}$ and the independent variable $\log _{10}$ (body mass) $(W)$. To determine the influence of factors other than body size on $\delta^{15} \mathrm{~N}$ we fitted our observations to linear mixed effects models that included part or all of a set of independent predictors comprising zone $(z$; benthic/pelagic), position ( $p$; canyon/slope) and cruise (c; March 2012, October 2012 and May 2013) as discrete, fixed factors and taxonomic group ( $t$; see Table 1 for the groups considered) as random factor (see Supplement). Those samples of giant squid, birds, and cetaceans that were not collected during a BIOCANT cruise were not included in this analysis. The most complex model, with as many variables and interactions as possible, can be represented as

$$
\begin{aligned}
\delta^{15} N_{i j} & =\left(\alpha_{0}+c_{i j}+z_{i j}+p_{i j}+c z_{i j}+z p_{i j}+c p_{i j}+c z p_{i j}\right) \\
& +\left(\beta_{1} c+\beta_{2} z+\beta_{3} p+\beta_{4} c z+\beta_{5} z p+\beta_{6} c p+\beta_{7} c z p\right) \\
& \log _{10} W_{i j}+a_{j}+b_{j} \log _{10} W_{i j}+\varepsilon_{i j} \\
& a_{j} \sim N\left(0, \sigma_{a}^{2}\right) b_{j} \sim N\left(0, \sigma_{b}^{2}\right) \varepsilon_{i j} \sim N\left(0, \sigma^{2}\right)
\end{aligned}
$$

where $\delta^{15} \mathrm{~N}_{\mathrm{ij}}$ is the $\delta^{15} \mathrm{~N}$ of the $i$ th individual of the $j$ th taxonomic group, the intercept $\alpha_{0}$ and the slope $\beta$ are the parameters of the fixed effect factors and their interactions; $a_{j}$ is the random intercept and $b_{j}$ the random slope. These random parameters add random variation among taxonomic group and are assumed to follow a normal distribution with mean of zero and variance of $\sigma_{a}^{2}$ and $\sigma_{b}^{2}$, respectively. The term $\varepsilon_{i j}$ is the residual associated with the $i$ th individual of the $j$ th taxonomic group from a normal distribution of residuals with mean of zero and variance of $\sigma^{2}$.

We followed a top-down model selection approach (Zuur et al. 2009) on models for each of all the possible combinations of factors and their interactions, and ranked them according to their second-order 
Akaike information criterion ( $\mathrm{AIC}_{\mathrm{c}}$ ), which reaches lowest values for simpler models with higher explanatory power. We chose the best model among those with comparable $\mathrm{AIC}_{\mathrm{c}}$ (i.e., $\Delta \mathrm{AIC}_{\mathrm{c}}<2$ for every additional parameter; Burnham and Anderson 2002) as the most parsimonious, with fewest parameters. To quantify the relative importance of each independent variable we summed the Akaike weights for each predictor with a $\log _{10} W$ interaction across all the models in which it occurred (Burnham and Anderson 2002). Marginal and conditional $R^{2}$ values (referred to variance explained by fixed factors and by both fixed and random factors, respectively) were calculated following the procedure outlined by Nakagawa and Schielzeth (2013). We performed all statistical analyses using $\mathrm{R}$, version 3.0.3 (R Core Team 2014) and the lme4 package to calculate linear mixed models (Bates et al. 2014).

\section{RESULTS}

\section{Environmental context of the BIOCANT cruises}

The seasonal dynamics of the $\mathrm{AC}$ correspond to those of a temperate sea, with water-column mixing during winter and stratification during summer, separated by a spring and an autumn phytoplankton bloom (e.g., Fernández and Bode 1991). Conditions during BIOCANT 1 (March 2012) were typical of the onset of the spring bloom. There was a slight, $0.5^{\circ} \mathrm{C}$ temperature gradient spanning the upper $200 \mathrm{~m}$ of the water column and associated with very high surface chl $a$ concentrations (Fig. 2). BIOCANT 3 (May 2013) corresponded to an early stratification period. There was an incipient subsurface chl $a$ maximum located between 20 and $70 \mathrm{~m}$ depth, which was associated with a weak thermocline $\left(2^{\circ} \mathrm{C}\right.$ gradient; Fig. 2). Last, BIOCANT 2 (October 2012) corresponded to a late stratification period, with a welldeveloped subsurface chl $a$ maximum located at $50 \mathrm{~m}$ depth and associated with a strong thermocline $\left(6^{\circ} \mathrm{C}\right.$ gradient; Fig. 2).

\section{Size-based trophic structure}

In the AC, we collected 897 specimens belonging to nine different phyla of both pelagic and benthic consumers with $\delta^{15} \mathrm{~N}$ ranging between $-0.3 \%$ and $18.5 \%$. Individual body size ranged from $3.03 \times 10^{-5}$ to $2.5 \times 10^{6} \mathrm{~g}$ (Fig. 3A). When grouped into representative taxonomic categories, the $\delta^{15} \mathrm{~N}$ ranged from 5.6\% \pm $0.7 \%$ o (mean $\pm \mathrm{SD})$ for Cymbulia peronii $(\mathrm{TL}=2)$ to $16.8 \%$ for the sperm whale $(\mathrm{TL}=5.3$; Fig. $3 \mathrm{~B}) . \delta^{15} \mathrm{~N}$ increased significantly with body size $(W)$ expressed either as individual values $\left(\delta^{15} \mathrm{~N}=10.07 \pm 0.08+1\right.$. $11 \pm 0.04 \log _{10} W$, parameter estimate $\pm \mathrm{SE}, P<0.001$, $R^{2}=0.51, n=852$; Fig. 3A), when grouped into taxonomic categories $\left(\delta^{15} \mathrm{~N}=10.07 \pm 0.34+0.95 \pm 0.15\right.$ $\log _{10} W, P<0.001, R^{2}=0.63, n=25$; Fig. $3 \mathrm{~B}$ ) or when binned in logarithmic size classes $\left(\delta^{15} \mathrm{~N}=9.69\right.$ $\pm 0.24+0.99 \pm 0.07 \log _{10} W, P<0.001, R^{2}=0.95$, $n=12$; Fig. 3C). The slopes and intercepts of those lines were not significantly different ( $t$ test for homogeneity of slopes, $F_{2,884}=0.410, P=0.663$; different intercept test, $F_{2.886} \stackrel{F_{2,884}}{=} 0.372, P=0.689$ ). Using Eq. 1 with Cymbulia peronii as baseline, the taxonomically aggregated equation translates to $\mathrm{TL}=3.32+0.28$ $\log _{10} W$. In general, the regression residuals of benthic consumers were positive, while the reverse was true for pelagic consumers, with most extreme cases in the asteroids $\left(\delta^{15} \mathrm{~N}\right.$ residual $\left.=3.62\right)$, the isopods $(3.16)$, and the dolphins (-3.5, Fig. 3B). The relationship between

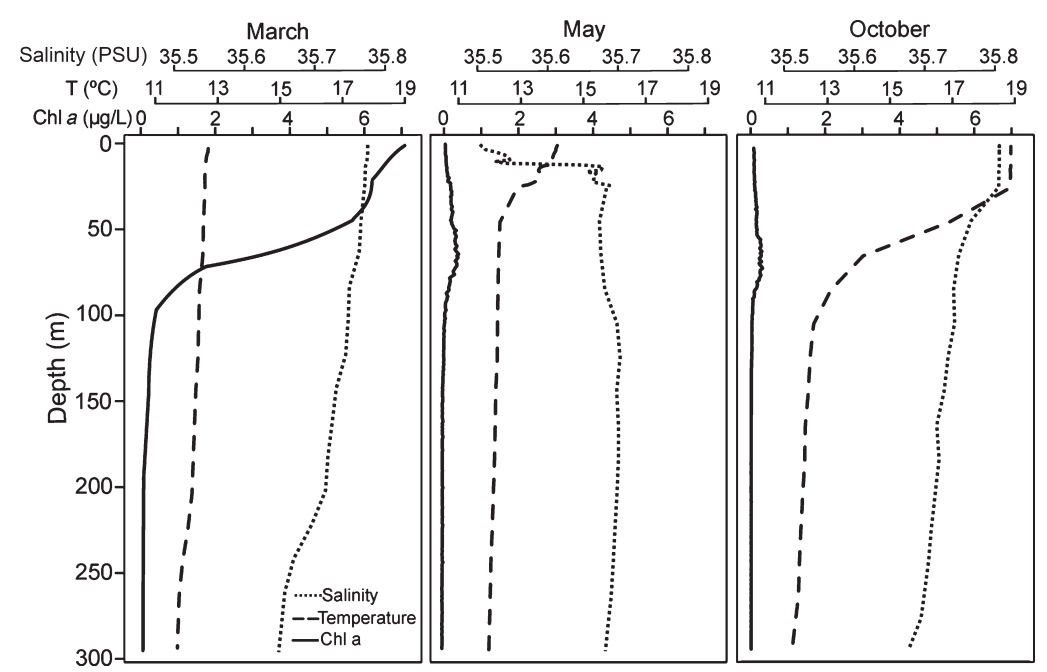

FIG. 2. Representative temperature (T), salinity, and chl $a$ profiles of each cruise in March (BIOCANT 1), May (BIOCANT 3), and October (BIOCANT 2). 


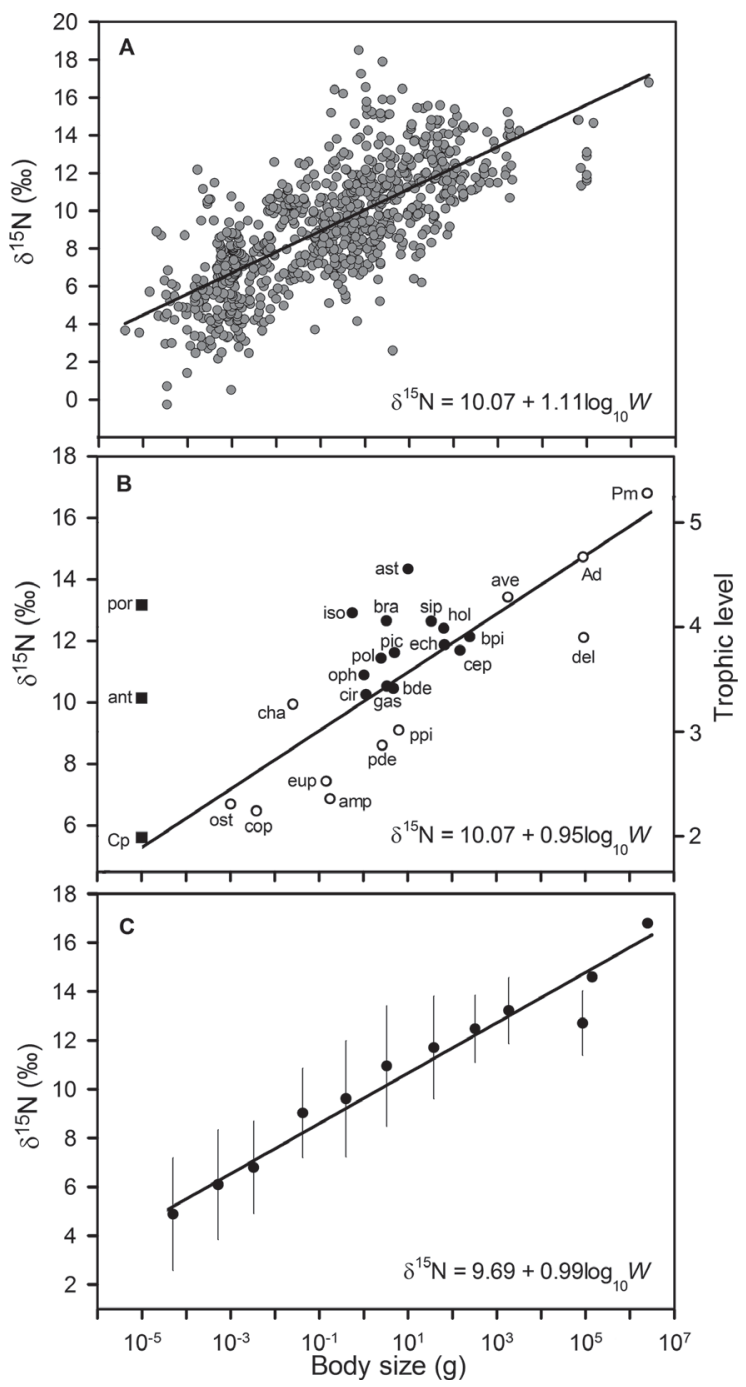

FIG. 3. (A) Relationship between $\delta^{15} \mathrm{~N}$ and individual body size $(W)$ for all organisms collected in the AC food web. (B) Relationship between mean $\delta^{15} \mathrm{~N}$ and mean body size of pelagic (open circles) and benthic (solid circles) taxonomic groups of the AC food web and their calculated trophic position. Codes as in Table 1. Squares refer to those taxonomic groups without body size data that were not included in the $\delta^{15} \mathrm{~N}$ vs. body size regression. For clarity, SDs are not shown. (C) Relationship between the $\delta^{15} \mathrm{~N}$ and size classes for the AC food web (mean \pm $\mathrm{SD})$.

$\delta^{15} \mathrm{~N}$ and body size was better described by a second order polynomial $\left(\mathrm{AIC}_{\mathrm{c}}=3727.12 ; R^{2}=0.52\right)$ than by a straight line $\left(\mathrm{AIC}_{\mathrm{c}}=3746.95 ; R^{2}=0.51\right)$. However, since the explained variance is similar, we used the straight line in order to compare our results with other systems.

\section{Variability not explained by body size}

The selected model among the possible linear mixed models generated, explained $67 \%$ of variance in $\delta^{15} \mathrm{~N}$ (model 7; Table 2). The most important factor is cruise (relative importance weight $=1$ ) and the model included this factor with different slope and intercept (Table 2), with steeper slope in BIOCANT 1 and 3 (i.e., March and May) than in the BIOCANT 2 cruise (i.e., October; Fig. 4). The model also included the factor zone (relative importance weight $=0.71$ ) with different intercept for each level (i.e., pelagic, benthic), indicating that benthic organisms had higher $\delta^{15} \mathrm{~N}$ than pelagic organisms, although this difference was more marked during BIOCANT 3 (May) than during the BIOCANT 1 and 2 cruises (i.e., March and October; Fig. 4) as determined from the cruise $\times$ zone factor interaction (model 7; Table 2). Taxonomic group entered the model as random factor with random slope and intercept (Table 3). Position (i.e., inside vs. outside the AC) did not provide enough explanatory power and so it is not included in the selected model (relative importance weight $=0.46$ ).

\section{DisCUSSION}

Trophic level vs. body size in the $A C$

Here we report the size-based, trophic structure of a whole ecosystem from copepods through benthic invertebrates and fishes to cetaceans and giant squids spanning a size range of nine orders of magnitude. Several previous studies have shown a significant increase in trophic position with body size at an individual level (e.g., Woodward et al. 2010, Gilljam et al. 2011) or when data were binned into size classes (e.g., Jennings et al. 2001, 2002a, Al-Habsi et al. 2008). However, grouping the data into taxonomic or functional categories resulted in weaker (e.g., Woodward et al. 2010, Gilljam et al. 2011) or nonsignificant trends [Jennings et al. (2001, 2002a), Layman et al. (2005), Al-Habsi et al. (2008), Tucker and Rogers (2014), but see Romanuk et al. (2011), who found positive correlations for fish species]. Such discrepancy has been interpreted as a symptom that size effects are due to intraspecific increases in trophic position during ontogeny (Jennings et al. 2001, Woodward et al. 2010). An alternative explanation may be that those studies were limited in their taxonomic breadth and/or body size range [e.g., fishes (Jennings et al. 2001, Layman et al. 2005, Al-Habsi et al. 2008); fishes and invertebrates (Jennings et al. 2002a, Woodward et al. 2010, Gilljam et al. 2011, Tucker and Rogers 2014)]. Our study, covering a more diverse taxonomic spectrum and a wider body size range, provides unequivocal evidence of size-based trophic structure, rendering similar estimates of the rate of increase in trophic level with size when using either individual, size-binned, or taxonomically aggregated data (Fig. 3).

Our findings cannot be blamed on the AC being a particularly different or unique ecosystem. It is 
TABLE 2. Fixed effects of best-fitting mixed models based on their Akaike information criterion corrected for sample size (AIC $)_{\mathrm{c}}$.

\begin{tabular}{lllllllllll}
\hline \hline \multicolumn{1}{l}{ Fixed effects } & & & & & & & & & \\
\hline Model & Cruise & Zone & Position & C $\times$ Z & K & AICc & $\Delta$ AICc & $w_{i}$ & $R_{(m)}^{2}$ & $R_{(c)}^{2}$ \\
\hline 1 & S\&I & S\&I & S\&I & I & 16 & 3258.54 & 0.00 & 0.24 & 0.58 & 0.68 \\
2 & S\&I & S\&I & I & I & 15 & 3259.46 & 0.93 & 0.15 & 0.58 & 0.68 \\
3 & S\&I & I & S\&I & I & 15 & 3259.80 & 1.27 & 0.13 & 0.57 & 0.67 \\
4 & S\&I & S\&I & & I & 14 & 3259.97 & 1.43 & 0.12 & 0.58 & 0.68 \\
5 & S\&I & S\&I & S\&I & S\&I & 18 & 3260.62 & 2.08 & 0.08 & 0.58 & 0.68 \\
6 & S\&I & I & I & I & 14 & 3260.66 & 2.12 & 0.08 & 0.57 & 0.67 \\
7 & S\&I & I & & I & $\mathbf{1 3}$ & $\mathbf{3 2 6 0 . 9 8}$ & $\mathbf{2 . 4 4}$ & $\mathbf{0 . 0 7}$ & $\mathbf{0 . 5 7}$ & $\mathbf{0 . 6 7}$ \\
8 & S\&I & S\&I & I & S\&I & 17 & 3261.27 & 2.73 & 0.06 & 0.58 & 0.68 \\
9 & S\&I & S\&I & & S\&I & 16 & 3261.73 & 3.19 & 0.05 & 0.58 & 0.68 \\
10 & S\&I & S\&I & S\&I & & 14 & 3264.95 & 6.42 & 0.01 & 0.57 & 0.67 \\
\hline
\end{tabular}

Notes: S\&I means that the factor (Cruise [C], Zone [Z], Position) or factor interaction $(\mathrm{C} \times \mathrm{Z}$ ) had a different slope and intercept for each level with body size, I means that only the intercept was different for each level. $K$ is the number of estimable parameters; $\Delta \mathrm{AIC}_{\mathrm{c}}, \mathrm{AIC}_{\mathrm{c}}$ differences relative to the smallest AIC value in the set of models; $w_{i}:$ probability that model $i$ is the best model. The selected best model is shown in boldface type.

certainly a very speciose system (Louzao et al. 2010), to the point of having been declared a European Union, Natura 2000 Site of Community Importance. However, the AC has five trophic levels, what is according to expectations for an aquatic food chain that includes marine mammals as top predators (Vander Zanden and Fetzer 2007). Our estimates for the slope of the $\delta^{15} \mathrm{~N}$ vs. $\log _{10} W$ linear relationship varied little, with values of $1.11,0.95$, or 0.99 when the data were considered individually, aggregated into taxonomic categories or binned into size classes, respectively (Fig. 3). The predator : prey body mass ratio (PPMR) can be calculated from these slopes as PPMR $=10^{(3.4 / \text { slope })}$ (Jennings et al. 2002a), yielding values of $1156: 1,3792: 1$ and 2718:1, respectively. These values compare well with other estimates based on stable isotopes like in the pelagic food web of the Galician upwelling system (4522:1; Bode et al. 2003), or the North Sea demersal fish community (1135:1; Jennings et al. 2001). They are also consistent with a compilation of marine food web data of individual-based analyses of gut content $\left(\sim 10^{3}\right.$; Nakazawa et al. 2011) and the estimation in the pelagic food web of the Tuesday Lake based on species abundance and body size (837.8; Cohen et al. 2003, Jonsson et al. 2005). However, other studies arrive to lower estimates of PPMR (434:1, Jennings et al. 2002a, 109:1, Jennings et al. 2002b, 424:1, Jennings and Warr 2003) possibly because they analyzed a narrower size range and only covering the benthic realm.

\section{Deviations from the allometric trend in $\delta^{15} \mathrm{~N}$}

Some of the taxonomic/functional groups deviate clearly from the $\delta^{15} \mathrm{~N}$ vs. $\log _{10} W$ regression line
(Fig. 3B), but those deviations make ecological sense. Asteroids, some of which are known to prey on megafauna like corals or sponges (Gale et al. 2013) showed the highest positive residuals. Chaetognaths exhibited the highest positive residuals among the pelagic groups (Fig. 3B). These animals predate on copepods (e.g., Feigenbaum 1991), which are one order of magnitude smaller in terms of body mass. This difference corresponds to a PPMR of approximately $10^{1}$, which is much smaller than a general PPMR of approximately $10^{3}$ as estimated from the slope of the $\delta^{15} \mathrm{~N}$ vs. $\log _{10} W$ regression line (Fig. 3B). It explains the observed increase of $\delta^{15} \mathrm{~N}$ of aggregated zooplankton samples with the amount of chaetognaths in the assemblages (Bode and Alvarez-Ossorio 2004). Such disproportionate influence prompts for caution in stable isotope studies where zooplankton are aggregated according to size fractions.

Isopods included in this study all belonged to Family Aegidae, which parasitize demersal fishes, with which they share a similar $\delta^{15} \mathrm{~N}$ (Pinnegar 2001). As parasites, those isopods exhibit an inverted PPMR, what accounts for their marked positive deviation from the regression line (Fig. 3B). This suggests that a study involving thorough assessment of the extraordinarily abundant parasites (Lafferty et al. 2008) would probably render a flat or inverted relationship between $\delta^{15} \mathrm{~N}$ and body mass. Dolphins showed the highest negative residual; hence they are eating smaller prey than expected for their size. Their $\delta^{15} \mathrm{~N} \quad(12.1 \%$, $\mathrm{TL}=3.9$ ) is in agreement with observations for the same species in other systems [i.e., Delphinus delphis and Stenella coeruleoalba; $11.7 \%$ and $10.8 \%$, respectively (Mèndez-Fernandez et al. 2012); 12.1\%o and 11.0\%o, respectively (Das et al. 2003); 13.1\%o, TL $=4.2$ 


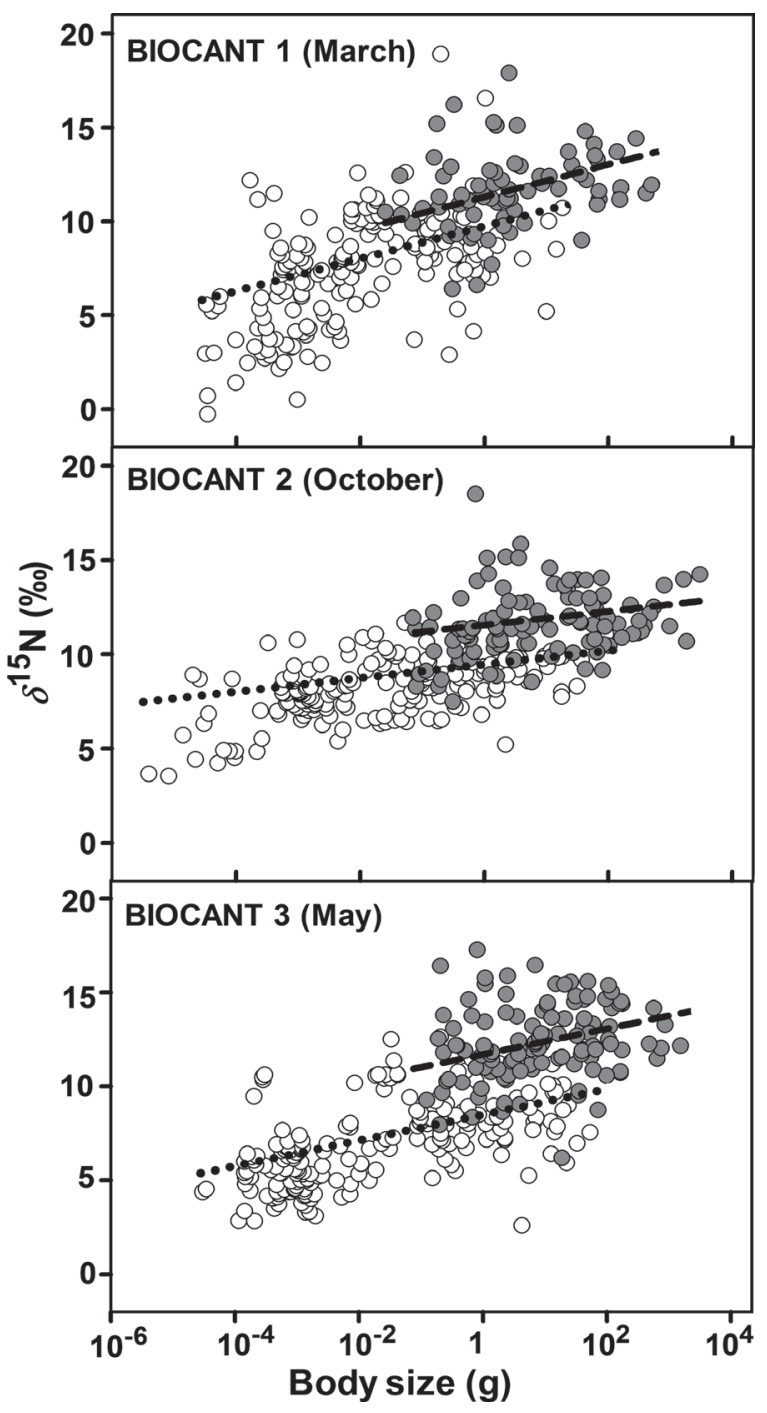

FIG. 4. Relationship between $\delta^{15} \mathrm{~N}$ and individual body size determined from the selected mixed-effect model for organisms collected in BIOCANT 1 (March 2012), BIOCANT 2 (October 2012), and BIOCANT 3 (May 2013).

for D. delphis (Bode et al. 2007)], and is consistent with a diet composed primarily of cephalopods and crustaceans and not fish as in other delphinids (Hassani et al. 1997).

In our study, a concave, second-order polynomial was better than a straight line in describing the $\delta^{15} \mathrm{~N}$ vs. $\log$ $W$ relationship, implying that large predators occupy a lower than expected trophic position. This agrees with a large body of empirical evidence pointing to a concave relationship or an increasing PPMR with predator size as expected from a decrease in transfer efficiency with predator size (Barnes et al. 2010). However, we have described our data using straight lines, because they explain nearly as much variance as a curve and because it is more convenient for comparison with other studies.

\section{Variability in $\delta^{15} N$ not explained by body mass}

One major result of our model selection approach was that the slope of the $\delta^{15} \mathrm{~N}$ vs. $\log _{10} W$ relationship changed through time (Fig. 4). These changes were mainly related to shifts in the $\delta^{15} \mathrm{~N}$ signature of the smallest organisms, which integrates shorter timescales and is therefore inherently more variable than that of larger organisms (O'Reilly and Hecky 2002). Moreover, this variation is probably related to a difference in the trophic structure of the ecosystem. The slopes were higher during BIOCANT 1 (March 2012) and BIOCANT 3 (May 2013; Table 3), which coincided with early stages of stratification in the water column and relatively high phytoplankton biomass (Fig. 2). In contrast, the slope was shallower during BIOCANT 2 (October 2012; Table 3), which corresponded to a situation of late stratification and low phytoplankton biomass (Fig. 2). In other words, the smallest organisms had higher $\delta^{15} \mathrm{~N}$ during early autumn, a pattern that is consistent with previous reports in other systems (Wainright and Fry 1994, Rolff 2000, Bănaru et al. 2013). This can be explained by a change in the $\delta^{15} \mathrm{~N}$ signature of phytoplankton, which is known to increase as the system evolves from an early stage of the production cycle based on new production to a late stage based on recycled production (Wainright and Fry 1994, Rolff 2000). This change is paralleled by a marked decrease in the ratio of autotrophic to heterotrophic biomass in the water column, favoring a shift from more herbivore to more omnivore or carnivore zooplankton diets as stratification progresses (Bănaru et al. 2013). Both mechanisms would lead to higher $\delta^{15} \mathrm{~N}$ content in the smallest organisms during late stratification, in autumn.

Our data suggest that the slope of the $\delta^{15} \mathrm{~N}$ vs. $\log _{10}$ $W$ relationship was similar and experienced the same seasonal oscillations in both benthic and pelagic organisms (Fig. 4). This, points to a similar PPMR and a similar cause for the trophic size structure in both systems, which is a fairly remarkable generalization. However, this pattern must be considered cautiously. The size range sampled was narrower for the benthic than for the pelagic organisms, and their $\delta^{15} \mathrm{~N}$ much more variable, what suggests a weaker size structure. This is to be expected from a system where deposit feeding predominates (such as the deep ocean, Iken et al. 2001) as opposed to a system based on phytoplankton production (Jennings et al. 2008). Thus, a similarity in regression slopes may not reflect an actual pattern, but a lack of statistical power to resolve any real difference.

In spite of their similarity in slope (hence PPMR), benthic organisms had $\delta^{15} \mathrm{~N} 2.1 \%$ units higher in average than that of pelagic organisms of the same size, as shown by a difference in the elevation of the $\delta^{15} \mathrm{~N}$ vs. $\log _{10} W$ regression lines in the mixed models (Table 3 , 
TABLE 3. Parameter estimates (with SE in parentheses) of the selected linear mixed effect model.

\begin{tabular}{llcr}
\hline \hline Cruise & Zone & $\beta_{1}$ & $\alpha$ \\
\hline BIO1 (March 2012) & Pelagic & $0.8629(0.1551)$ & $9.7502(0.4254)$ \\
BIO1 (March 2012) & Benthic & $0.8629(0.1551)$ & $11.3099(0.3453)$ \\
BIO2 (October 2012) & Pelagic & $0.3622(0.1387)$ & $9.4699(0.3939)$ \\
BIO2 (October 2012) & Benthic & $0.3622(0.1387)$ & $11.5562(0.3364)$ \\
BIO3 (May 2013) & Pelagic & $0.6851(0.1384)$ & $8.8498(0.3880)$ \\
BIO3 (May 2013) & Benthic & $0.6851(0.1384)$ & $11.7056(0.3244)$ \\
\hline
\end{tabular}

Notes: Random effects are $\sigma_{a}^{2}=1.011, \sigma_{a}^{2}=1.011, \sigma^{2}=2.910$. Best selected model equation: $\delta^{15} N_{i j}=\alpha+\beta_{1} c \log { }_{10} W_{i j}+a_{j}+$ $b_{j} \log _{10} W_{i j}+\varepsilon_{i j}$, where $\alpha=\alpha_{0}+c_{i j}^{a}+z_{i j}+c z_{i j}$, the intercept $\alpha_{0}$ and the slope $\beta$ are the parameters of the fixed effect factors and their interactions, $a_{j}$ is the random intercept and $b_{j}$ the random slope, $c$ is cruise, $z$ is zone, and $W$ is body mass $(\mathrm{g})$. The term $\varepsilon_{i j}$ is the residual associated with the $i$ th individual of the $j$ th taxonomic group from a normal distribution of residuals with mean of zero and variance of $\sigma^{2}$.

Fig. 4). This result is consistent with previous observations of high $\delta^{15} \mathrm{~N}$ in benthic organisms (Saino and Hattori 1980, Mintenbeck et al. 2007), and makes sense for a predominantly detrital food web fueled by sinking material and sediment enriched in ${ }^{15} \mathrm{~N}$ due to preferential utilization of the light isotope during microbial degradation (Saino and Hattori 1980, Mintenbeck et al. 2007). Such difference in $\delta^{15} \mathrm{~N}$ translates into a difference of 0.6 trophic levels, although this depends directly on our assumption of a common baseline for both systems. For example, if we had a putative benthic herbivore with a $\delta^{15} \mathrm{~N}=9 \%$, and if we used this organism as baseline for the benthic consumers, then the apparent difference of 0.6 trophic levels with the pelagic consumers would have vanished. In our opinion, the interesting pattern here is not the absolute value of the difference but its marked seasonal oscillation. It was smaller during the early stages of the spring phytoplankton bloom in March (1.5\%o, BIOCANT 1) and larger during an intermediate or a late stratification stage $(2.8 \%$ and $2.1 \%$ during BIOCANT 3 and BIOCANT 2 in May and October, respectively; Fig. 4). It is precisely during the early spring phytoplankton bloom that we expect intense downward fluxes of particulate matter produced at the ocean surface (Olli et al. 2002). Therefore, our results suggest that these intense yet ephemeral inputs have a pervasive effect along the size spectrum of the benthic system and that stable isotopes can be used to detect changes in the degree of coupling among water column processes and the benthos.

Our study did not reveal significant differences in $\delta^{15} \mathrm{~N}$ enrichment between organisms that inhabited the main axis of the canyon and those on the adjacent slope. Therefore, the size structure of the benthic system within the 1200-4700 m depth range and the overlying water column seems uniform. Submarine canyons channel large volumes of sediment of terrestrial origin (Canals et al. 2006), and the $\mathrm{AC}$ is located right off the main river outflow to the Cantabrian Slope (Nalón River, Fig. 1;
$109 \mathrm{~m}^{3} / \mathrm{s}$ annual average flow; Prego and Vergara 1998) so an input of organic matter of terrestrial origin is to be expected within the canyon. Our data suggest that this input does not alter the body size structure of the food web significantly, which can therefore be reasonably extrapolated to other regions of the Cantabrian shelf. Identification of the sources at the base of the food web will only be achieved through investigation of the isotopic composition of elements other than nitrogen (i.e., carbon). However, our study shows that $\delta^{15} \mathrm{~N}$ may render very useful information about the structure and dynamics of a very complex ecosystem, which would be prohibitively difficult to obtain following more traditional approaches.

\section{ACKNOWLedgments}

This study was carried out within the framework of projects DOSMARES (ref. CTM2012-2180-CO3-02) and SCAPA (ref. CTM2013-45089) from the Ministry of Science and Innovation, Spanish Government. S. Romero-Romero was supported by a FPU fellowship (ref. 12/00851) from the Ministry of Education, Culture and Sports. We thank Ricardo Anadón, Arturo Castellón, Julio Arrontes, and all the scientists and the crew of B/O Sarmiento de Gamboa and the Unidad de Tecnología Marina (UTM) for their help with sampling. José Antonio Pis, Fernando Jiménez and Lucía García from the Centro de Experimentación Pesquera (CEP) of the Asturias Principality Government identified the fish specimens in this study. We are also grateful to Carlos Cáceres and Ricardo GonzálezGil for their assistance with the statistical analysis. We thank Luis Laria and CEPESMA for granting us access to precious cetacean and giant squid samples and to the CEP and SEO/ BirdLife for bird samples. This is a contribution of the Asturias Marine Observatory.

\section{Literature Cited}

Abràmoff, M. D., P. J. Magalhães, and S. J. Ram. 2004. Image processing with imageJ. Biophotonics International 11:36-41.

Akin, S., and K. O. Winemiller. 2008. Body size and trophic position in a temperate estuarine food web. Acta Oecologica 33:144-153. 
Al-Habsi, S., C. Sweeting, N. Polunin, and N. Graham. 2008. $\delta^{15} \mathrm{~N}$ and $\delta^{13} \mathrm{C}$ elucidation of size-structured food webs in a Western Arabian Sea demersal trawl assemblage. Marine Ecology Progress Series 353:55-63.

Bănaru, D., F. Carlotti, A. Barani, G. Gregori, N. Neffati, and M. Harmelin-Vivien. 2013. Seasonal variation of stable isotope ratios of size-fractionated zooplankton in the Bay of Marseille (NW Mediterranean Sea). Journal of Plankton Research 36:145-156.

Barnes, C., D. Maxwell, D. Reuman, and S. Jennings. 2010. Global patterns in predator-prey size relationships reveal size dependency of trophic transfer efficiency. Ecology 91:222-232.

Bates, D., M. Maechler, B. Bolker, and S. Walker. 2014. lme4: linear mixed-effects models using Eigen and S4. R package version 1.1-7. http://cran.r-project.org/package=lme4.

Bode, A., and M. Alvarez-Ossorio. 2004. Taxonomic versus trophic structure of mesozooplankton: a seasonal study of species succession and stable carbon and nitrogen isotopes in a coastal upwelling ecosystem. ICES Journal of Marine Science 61:563-571.

Bode, A., P. Carrera, and S. Lens. 2003. The pelagic foodweb in the upwelling ecosystem of Galicia (NW Spain) during spring: natural abundance of stable carbon and nitrogen isotopes. ICES Journal of Marine Science 60:11-22.

Bode, A., M. Alvarez-Ossorio, M. E. Cunha, S. Garrido, J. Peleteiro, C. Porteiro, L. Valdés, and M. Varela. 2007. Stable nitrogen isotope studies of the pelagic food web on the Atlantic shelf of the Iberian Peninsula. Progress in Oceanography $74: 115-131$

Burnham, K. P., and D. R. Anderson. 2002. Model selection and multimodel inference: a practical information-theoretic approach. Springer, New York, New York, USA.

Canals, M., P. Puig, X. D. de Madron, S. Heussner, A. Palanques, and J. Fabres. 2006. Flushing submarine canyons. Nature 444:354-357.

Cohen, J. E., T. Jonsson, and S. R. Carpenter. 2003. Ecological community description using the food web, species abundance, and body size. Proceedings of the National Academy of Sciences of the United States of America 100:1781-1786.

Das, K., C. Beans, L. Holsbeek, G. Mauger, S. D. Berrow, E. Rogan, and J. M. Bouquegneau. 2003. Marine mammals from northeast Atlantic: relationship between their trophic status as determined by $\delta^{13} \mathrm{C}$ and $\delta^{15} \mathrm{~N}$ measurements and their trace metal concentrations. Marine Environmental Research $56: 349-365$.

De Leo, F. C., C. R. Smith, A. A. Rowden, D. A. Bowden, and M. R. Clark. 2010. Submarine canyons: hotspots of benthic biomass and productivity in the deep sea. Proceedings of the Royal Society of London B 277:2783-2792.

Dickie, L. M., S. R. Keer, and P. R. Boudreau. 1987. Sizedependent processes underlying regularities in ecosystem structure. Ecological Monographs 57:233-250.

Feigenbaum, D. L. 1991. Food and feeding behavior. Pages 4554 in Q. Bone, H. Kapp and A. C. Pierrot-Bults, editors. The biology of chaetognaths. Oxford University Press, Oxford, UK.

Fernández, E., and A. Bode. 1991. Seasonal patterns of primary production in the Central Cantabrian Sea (Bay of Biscay). Scientia Marina 55:629-636.

France, R., M. Chandler, and R. Peters. 1998. Mapping trophic continua of benthic foodwebs: body size $-\delta^{15} \mathrm{~N}$ relationships. Marine Ecology Progress Series 174:301-306.

Fry, B., and R. Quiñones. 1994. Biomass spectra and stable isotope indicators of trophic level in zooplankton of the northwest Atlantic. Marine Ecology Progress Series 112:201-204.
Gale, K. S. P., J. F. Hamel, and A. Mercier. 2013. Trophic ecology of deep-sea Asteroidea (Echinodermata) from eastern Canada. Deep Sea Research Part I: Oceanographic Research Papers 80:25-36.

Gilljam, D., A. Thierry, F. K. Edwards, D. Figueroa, A. T. Ibbotson, J. I. Jones, R. B. Lauridsen, O. L. Petchey, G. Woodward, and B. Ebenman. 2011. Seeing double: size-based and taxonomic views of food web structure. Advances in Ecological Research 45:67-133.

Gómez-Ballesteros, M., et al. 2014. Geomorphology of the Avilés Canyon System, Cantabrian Sea (Bay of Biscay). Deep Sea Research Part II: Topical Studies in Oceanography 106:99-117.

Hassani, S., L. Antoine, and V. Ridoux. 1997. Diets of albacore, Thunnus alalunga, and dolphins Delphinus delphis and Stenella coeruleoalba, caught in the Northeast Atlantic albacore drift-net: a progress report. Journal of Northwest Atlantic Fishery Science 22:119-123.

Hebert, P. D. N., S. Ratnasingham, and J. R. de Waard. 2003. Barcoding animal life: cytochrome $\mathrm{c}$ oxidase subunit 1 divergences among closely related species. Proceedings of the Royal Society of London B 270:S96-S99.

Hyslop, E. J. 1980. Stomach contents analysis - a review of methods and their application. Journal of Fish Biology $17: 411-429$.

Iken, K., T. Brey, U. Wand, J. Voigt, and P. Junghans. 2001. Food web structure of the benthic community at the Porcupine Abyssal Plain (NE Atlantic): a stable isotope analysis. Progress in Oceanography 50:383-405.

Jacob, U., et al. 2011. The role of body size in complex food webs. A cold case. Advances in Ecological Research 45:181223.

Jennings, S., and N. Dulvy. 2005. Reference points and reference directions for size-based indicators of community structure. ICES Journal of Marine Science 62:397-404.

Jennings, S., and K. J. Warr. 2003. Smaller predator-prey body size ratios in longer food chains. Proceedings of the Royal Society of London B 270:1413-1417.

Jennings, S., J. K. Pinnegar, N. V. C. Polunin, and T. W. Boon. 2001. Weak cross-species relationships between body size and trophic level belie powerful size-based trophic structuring in fish communities. Journal of Animal Ecology 70:934 944.

Jennings, S., J. Pinnegar, N. Polunin, and K. Warr. 2002a. Linking size-based and trophic analyses of benthic community structure. Marine Ecology Progress Series 226:77-85.

Jennings, S., K. J. Warr, and S. Mackinson. 2002b. Use of size-based production and stable isotope analyses to predict trophic transfer efficiencies and predator-prey body mass ratios in food webs. Marine Ecology Progress Series 240:11-20.

Jennings, S., C. Barnes, J. Sweeting, and N. V. C. Polunin. 2008. Application of nitrogen stable isotope analysis in size-based marine food web and macroecological research. Rapid Communications in Mass Spectrometry 22:1673-1680.

Jonsson, T., J. Cohen, and S. Carpenter. 2005. Food webs, body size, and species abundance in ecological community description. Advances in Ecological Research 36:1-84.

Lafferty, K. D., et al. 2008. Parasites in food webs: the ultimate missing links. Ecology Letters 11:533-546.

Layman, C., K. Winemiller, D. Arrington, and D. Jepsen. 2005. Body size and trophic position in a diverse tropical food web. Ecology 86:2530-2535.

Louzao, M., N. Anadón, J. Arrontes, C. Álvarez-Claudio, D. M. Fuente, F. Ocharan, A. Anadón, and J. L. Acuña. 2010. Historical macrobenthic community assemblages in the Avilés Canyon, N Iberian Shelf: baseline biodiversity information 
for a marine protected area. Journal of Marine Systems 80:47-56.

Mèndez-Fernandez, P., et al. 2012. Foraging ecology of five toothed whale species in the Northwest Iberian Peninsula, inferred using carbon and nitrogen isotope ratios. Journal of Experimental Marine Biology and Ecology 413:150-158.

Mengerink, K. J., et al. 2014. A call for deep-ocean stewardship. Science 344:696-698.

Minagawa, M., and E. Wada. 1984. Stepwise enrichment of ${ }^{15} \mathrm{~N}$ along food chains: further evidence and the relation between $\delta^{15} \mathrm{~N}$ and animal age. Geochimica et Cosmochimica Acta 48:1135-1140.

Mintenbeck, K., U. Jacob, R. Knust, W. E. Arntz, and T. Brey. 2007. Depth-dependence in stable isotope ratio $\delta^{15} \mathrm{~N}$ of benthic POM consumers: the role of particle dynamics and organism trophic guild. Deep Sea Research Part I: Oceanographic Research Papers 54:1015-1023.

Nakagawa, S., and H. Schielzeth. 2013. A general and simple method for obtaining $R^{2}$ from generalized linear mixed-effects models. Methods in Ecology and Evolution 4:133-142.

Nakazawa, T., M. Ushio, and M. Kondoh. 2011. Scale dependence of predator-prey mass ratio: determinants and applications. Advances in Ecological Research 45:269-302.

Olli, K., C. Wexels Riser, P. Wassmann, T. Ratkova, E. Arashkevich, and A. Pasternak. 2002. Seasonal variation in vertical flux of biogenic matter in the marginal ice zone and the central Barents Sea. Journal of Marine Systems 38:189-204.

O'Reilly, C. M., and R. E. Hecky. 2002. Interpreting stable isotopes in food webs: recognizing the role of time averaging at different trophic levels. Limnology and Oceanography 47:306309.

Persaud, A. D., P. J. Dillon, L. A. Molot, and K. E. Hargan. 2011. Relationships between body size and trophic position of consumers in temperate freshwater lakes. Aquatic Sciences 74:203-212.

Peters, R. H. 1983. The ecological implications of body size. Cambridge University Press, Cambridge, UK.

Pinnegar, J. 2001. Unusual stable isotope fractionation patterns observed for fish host-parasite trophic relationships. Journal of Fish Biology 59:494-503.

Pinnegar, J. K., S. Jennings, C. M. O. Brien, and N. V. C. Polunin. 2002. Long-term changes in the trophic level of the Celtic Sea fish community and fish market price distribution. Journal of Applied Ecology 39:377-390.

Post, D. 2002. Using stable isotopes to estimate trophic position: models, methods, and assumptions. Ecology 83:703-718.

Prego, R., and J. Vergara. 1998. Nutrient fluxes to the Bay of Biscay from Cantabrian rivers (Spain). Acta Oecologica 21:271-278.
R Core Team. 2014. R: a language and environment for statistical computing. R Foundation for Statistical Computing, Vienna, Austria. http://www.R-project.org/

Ramirez-Llodra, E., et al. 2011. Man and the last great wilderness: human impact on the deep sea. PLoS ONE 6:e22588.

Rochet, M.-J. and V. M. Trenkel. 2003. Which community indicators can measure the impact of fishing? A review and proposals. Canadian Journal of Fisheries and Aquatic Sciences 60:86-99.

Rolff, C. 2000. Seasonal variation in $\delta^{13} \mathrm{C}$ and $\delta^{15} \mathrm{~N}$ of sizefractionated plankton at a coastal station in the northern Baltic proper. Marine Ecology Progress Series 203:47-65.

Romanuk, T. N., A. Hayward and J. A. Hutchings. 2011. Trophic level scales positively with body size in fishes. Global Ecology and Biogeography 20:231-240.

Saino, T. and A. Hattori. $1980 .{ }^{15} \mathrm{~N}$ natural abundance in oceanic suspended particulate matter. Nature 283:752-754.

Sheldon, R. W., A. Prakash and H. Sutcliffe. 1972. The size distribution of particles in the ocean. Limnology and Oceanography 17:327-340.

Tucker, M. and T. Rogers. 2014. Examining predator-prey body size, trophic level and body mass across marine and terrestrial mammals. Proceedings of the Royal Society of London B 281: 20142103. doi:10.1098/rspb.2014.2103.

Valls, M., C. J. Sweeting, M. P. Olivar, M. L. Fernández de Puelles, C. Pasqual, N. V. C. Polunin and A. Quetglas. 2014. Structure and dynamics of food webs in the water column on shelf and slope grounds of the western Mediterranean. Journal of Marine Systems 138:171-181.

Vander Zanden, J. M. and W. W. Fetzer. 2007. Global patterns of aquatic food chain length. Oikos 116:1378-1388.

Vander Zanden, M. J. and J. Rasmussen. 2001. Variation in $\delta^{15} \mathrm{~N}$ and $\delta^{13} \mathrm{C}$ trophic fractionation: implications for aquatic food web studies. Limnology and Oceanography 46:2061-2066.

Wainright, S. C. and B. Fry. 1994. Seasonal variation of the stable isotopic compositions of coastal marine plankton from Woods Hole. Massachusetts and Georges Bank. Estuaries 17:552.

Warren, P. H. 1989. Spatial and temporal variation in the structure of a freshwater food web. Oikos 55:299-311.

Woodward, G., B. Ebenman, M. Emmerson, J. M. Montoya, J. M. Olesen, A. Valido and P. H. Warren. 2005. Body size in ecological networks. Trends in Ecology \& Evolution 20:402-409.

Woodward, G., J. Blanchard, B. Lauridsen, F. K. Edwards, J. I. Jones, D. Figueroa, P. H. Warren and O. L. Petchey. 2010. Individual-based food webs: species identity, body size and sampling effects. Advances in Ecological Research 43:211-266.

Zuur, A. F., E. N. Ieno, N. J. Walker, A. A. Saveliev and G. M. Smith. 2009. Mixed effects models and extensions in ecology with R. Springer, New York, New York, USA.

\section{SUPPORTING INFORMATION}

Additional supporting information may be found in the online version of this article at http://onlinelibrary.wiley.com/ doi/10.1890/15-0234.1/suppinfo 